\title{
The contribution of domestic animals to the transmission of schistosomiasis japonica in the Lindu Subdistrict of the Central Sulawesi Province, Indonesia
}

\author{
Novericko Ginger Budionoㄹ, Fadjar Satrija ${ }^{1,2}$, Yusuf Ridwan ${ }^{1,2}$, Ekowati Handharyani ${ }^{3}$ and Sri Murtini ${ }^{1,2}$ \\ 1. Parasitology and Medical Entomology Study Program, Graduate School, IPB University, Bogor, Indonesia; \\ 2. Department of Animal Infectious Diseases and Veterinary Public Health, Faculty of Veterinary Medicine, IPB University, \\ Bogor, Indonesia; 3. Department of Veterinary Clinic, Reproduction, and Pathology, Faculty of Veterinary Medicine, IPB \\ University, Bogor, Indonesia. \\ Corresponding author: Fadjar Satrija, e-mail: fadjar_s@apps.ipb.ac.id \\ Co-authors: NGB: novericko_ginger@apps.ipb.ac.id, YR: yridwan@apps.ipb.ac.id, EH: ekowatieko@apps.ipb.ac.id, \\ SM: srimurtini_fkh@apps.ipb.ac.id \\ Received: 17-06-2019, Accepted: 03-09-2019, Published online: 23-10-2019
}

doi: www.doi.org/10.14202/vetworld.2019.1591-1598 How to cite this article: Budiono NG, Satrija F, Ridwan Y, Handharyani E, Murtini S (2019) The contribution of domestic animals to the transmission of schistosomiasis japonica in the Lindu Subdistrict of the Central Sulawesi Province, Indonesia, Veterinary World, 12(10): 1591-1598.

\begin{abstract}
Background and Aim: Schistosomiasis is endemic in Indonesia and is found in three remote areas in Central Sulawesi Province. Non-human mammals serve as reservoir hosts, meaning the disease is zoonotic. The previous schistosomiasis studies in animals from the Lindu Subdistrict did not determine which domestic animal species can serve as the primary source of transmission. No animals have been treated in Indonesia to control the disease; therefore, the parasite's life cycle is not blocked entirely. This study aimed to determine the prevalence and identify the risk factors associated with, Schistosoma japonicum infection in animals, and identify animals' relative contributions to S. japonicum transmission in the Lindu Subdistrict.

Materials and Methods: A cross-sectional survey of S. japonicum infected animals was conducted in five villages of the Lindu Subdistrict. Fecal samples were collected from 134 selected animals (13 cattle, 26 buffaloes, 28 horses, 59 pigs, and 8 dogs). S. japonicum infection and infection intensity were determined using the Danish Bilharziasis Laboratory method. Environmental contamination with schistosome eggs was measured. The data were analyzed using a Chi-square test.

Results: The overall prevalence of schistosomiasis was $32.9 \%$, with the prevalence of infection in each species of animal at $61.5 \%$ in cattle, $42.3 \%$ in buffaloes, $25.0 \%$ in horses, $35.6 \%$ in pigs, and $12.5 \%$ in dogs. Free-range pigs were 8.667 times more likely to have $S$. japonicum infection than pigs kept in cages. Buffaloes, cattle, and horses were the primary sources of $S$. japonicum egg contamination, with relative transmission indices of $59.15 \%, 22.80 \%$, and $10.61 \%$, respectively.

Conclusion: Bovines and horses are the main contributors to schistosomiasis transmission in the Lindu Subdistrict. In conjunction with other schistosomiasis control programs, the government should treat infected animals living within endemic areas where there are high infection rates of $S$. japonicum.
\end{abstract}

Keywords: coprology, mammalian animals, schistosomiasis, transmission, zoonosis.

\section{Introduction}

Schistosomiasis is a parasitic disease, which contributes to global public health and economic problems. Globally, about 250 million people have contracted the disease [1], and more than 800 million people are at risk of infection [2]. Helminth parasites from the genus of Schistosoma are the etiological agents. Six species cause infections in humans, namely, Schistosoma mansoni, Schistosoma japonicum, Schistosoma haematobium, Schistosoma intercalatum, Schistosoma guineensis, and Schistosoma mekongi, which are endemic in tropical and subtropical

Copyright: Budiono, et al. Open Access. This article is distributed under the terms of the Creative Commons Attribution 4.0 International License (http://creativecommons.org/licenses/ by/4.0/), which permits unrestricted use, distribution, and reproduction in any medium, provided you give appropriate credit to the original author(s) and the source, provide a link to the Creative Commons license, and indicate if changes were made. The Creative Commons Public Domain Dedication waiver (http:// creativecommons.org/publicdomain/zero/1.0/) applies to the data made available in this article, unless otherwise stated. countries [3]. Schistosomiasis japonica, a term for infection by $S$. japonicum, can be found in Indonesia, the Philippines, and the People's Republic of China. Infection by $S$. japonicum is zoonotic because, in addition to humans, domestic, and wild mammals can also act as reservoir hosts. The nature of such an unusual zoonotic disease complicates control measures [4]. The intermediate host of $S$. japonicum in Indonesia is the snail, from the species of Oncomelania hupensis lindoensis [4]. Infection by $S$. japonicum in humans causes anemia, growth disorders, disorders of chronic abdominal organs (portal vein enlargement and enlargement of the liver and spleen), fibrosis of the liver [5], and even death [6].

In Indonesia, 28 villages in two districts (Sigi District and Poso District) of the Central Sulawesi Province are endemic for schistosomiasis. The prevalence of human schistosomiasis in Indonesia has fluctuated in the past decade. The prevalence in the Napu Valley has decreased, but there is an upward trend overall [7]. Since 2005, a control program has 
led to a decrease in prevalence from $37 \%$ to $1 \%$ or less in Lindu and Napu, but in 2008-2011, the prevalence increased between 0.3 and $4.8 \%$ in Napu and 0.8 and $3.2 \%$ in Lindu [4]. The first reported infection with $S$. japonicum in Bada, in 2008, with a prevalence of $0.5 \%$; a survey conducted in 2010 showed an increase in incidence to $5.9 \%$ [7]. Research on each mammalian species' contribution to disease transmission by measuring the relative transmission index (RTI) is essential to developing a strategy for controlling schistosomiasis [8]. The previous studies in the Philippines and China have revealed that bovines are the primary source of schistosomiasis transmission [5,9], despite the differences in diagnostic tools used for fecal examination. A miracidia hatching test has been used routinely in China [10], and the Danish Bilharziasis Laboratory (DBL) technique has been used extensively in the Philippines [11] to detect $S$. japonicum infection among domestic animals. In the endemic areas of Indonesia, the significance of animals, especially domestic animals living close to the community, in schistosomiasis transmission is still unknown. As there is no vaccine for schistosomiasis, praziquantel is the primary treatment for infected humans and animal reservoir hosts [12].

The current study conducted with the aims to (1) determine the prevalence of schistosomiasis in animals, (2) identify risk factors for schistosomiasis in domestic animals, and (3) determine the relative roles of domestic animals in $S$. japonicum transmission in the Lindu Subdistrict, Province of Central Sulawesi, Indonesia.

\section{Materials and Methods}

\section{Ethics approval and Informed consent}

The authors obtained ethical clearance from the Animal Ethics Committee, Institute of Research and Community Development, IPB University No. 69-2017. Appropriate informed consent was obtained to collect animal stool samples, and animal sampling was performed using an approved protocol.

\section{Study design and study area}

This cross-sectional study, conducted in August 2017 , consisted of measuring the rate and the infection intensity of $S$. japonicum, associated risk factors, and the relative contribution of a number of animals in disease transmission. The animal owners were interviewed using a questionnaire to record potential risk factors. Geographically, the Lindu Subdistrict is located in $1^{\circ} 13^{\prime} 37^{\prime} \mathrm{S}$ until $1^{\circ} 30^{\prime} 15^{\prime} \mathrm{S}$ and $120^{\circ} 00^{\prime} 43^{\prime \prime} \mathrm{E}$ until $120^{\circ} 17^{\prime} 17^{\prime}$ 'E. Topographically, the Lindu Subdistrict is upland and a valley, with a total area of 11962.5 Ha. The Lindu Subdistrict consists of five villages, namely, Puroo, Langko, Tomado, Anca, and Olu [13].

Sample size, sample collection, and stool examination

The sample size was determined using the Thrusfield formula [14], with a confidence interval (CI) of $95 \%$, an expected prevalence of $24.5 \%$, and an error rate of $8 \%$. Using this formula, the minimum sample size was determined to be 114 . A total of 134 animal stool samples (from 13 cattle, 26 buffaloes, 28 horses, 59 pigs, and 8 dogs) were collected from five villages in the Lindu Subdistrict. The authors interviewed the animal owners to find out the characteristics of the owners and animals, such as age, sex, and state of care.

All animal owners were asked not to release the animals in the morning before the stool samples were collected. Stool samples were collected from the animals by veterinarians or trained veterinary paramedics. Each stool sample taken was labeled (location, code, animal species, sex, animal age, owner's name, the animal husbandry management, and sampling date). Animal feces were taken as directly as possible, through rectal palpation or from individual cages, at a minimum of $20 \mathrm{~g}$. Animal samples were obtained by limiting the animal to a pen or binding the animal until the samples were collected. If there was no individual animal cage, animals were tied, and then, the feces that were excreted the next morning were collected. The laboratory work was performed at the Helminthology Laboratory, Faculty of Veterinary Medicine, IPB University.

\section{DBL technique}

The DBL technique was a combination technique involving filtration and sedimentation. Briefly, a total of $5 \mathrm{~g}$ of fecal matter were weighed, dissolved in $50 \mathrm{~mL}$ $0.9 \% \mathrm{NaCl}$, homogenized, and filtered using multilevel filters (filter sizes 400,100 , and $40 \mu \mathrm{m}$ ). The mixture of fecal materials retained in the $40 \mu \mathrm{m}$ filter was put into a Baermann glass with $0.9 \% \mathrm{NaCl}$ and left in a dark room for $10 \mathrm{~min}$. The sediment was transferred to a test tube to be centrifuged and resuspended in $0.9 \%$ $\mathrm{NaCl}$ to a total volume of $2.25 \mathrm{~mL}$. Then, $150 \mu \mathrm{L}$ of the mixture was pipetted and added to $850 \mu \mathrm{L} 0.9 \% \mathrm{NaCl}$ to a total of $1 \mathrm{~mL}$ in the counting chamber. Eggs were counted 3 times to determine the number of eggs per gram of stool. If the number of eggs calculated between repeated measures was more than $10 \%$ different, or the stool size was smaller than $5 \mathrm{~g}$, then the calculation involved dividing the total number of eggs estimated from three counting chambers by the weight of the actual sample and then multiplying by 5 [15].

\section{Measurement of environmental contamination} parameters

\section{Total daily egg output}

The stool weight of each species was assumed based on the previous research [16,17]. In China and the Philippines, cattle and buffaloes can excrete $25-50 \mathrm{~kg}$ of feces per head every day. In this study, $25 \mathrm{~kg}$ was used as a conservative number for cattle and buffalo excretion. In Indonesia, the same data were accounted for cattle and buffalo. Horses were determined to excrete $10 \mathrm{~kg} /$ day [16]. Data regarding the prevalence and intensity of infection were used to calculate the level of contamination of feces with eggs 
based on the DBL method. Measurement of the total daily egg excretion (TDEE) for each animal species was conducted using the following formula:

$$
\text { TDEE }=\frac{\sum \text { Infected animal(s) }}{\sum \text { Examined animal }(\mathrm{s})} \times \sum \text { Animals in the }
$$

area $\times$ Egg per gram of feces $\times$ Fecal weight $(\mathrm{g})$

\section{Animal contamination index (ACI)}

The ACI for each species of animal was calculated using a formula that has been previously published [18]. ACI=Arithmetic mean of egg per gram of feces $\times \sum$ infected animal $(\mathrm{s}) \times$ fecal weight $(\mathrm{g})$.

\section{$R T I$}

The RTI was measured using the formula as follows [17]:

$$
\begin{gathered}
\sum \text { The population of a species } \times \\
\text { Prevalence } \times \text { Daily fecal excretion } \\
\text { RTI }=\frac{\text { of a species } \times \text { EPG }}{\sum_{\mathrm{i}=1}^{\mathrm{n}}\left(\sum \text { The population of a species } \times\right.} \\
\begin{array}{l}
\text { Prevalence } \times \text { Daily fecal excretion } \\
\text { of a species } \times \text { EPG })
\end{array}
\end{gathered}
$$

\section{Statistical analysis}

Data were entered into Microsoft Excel 2010. A Chi-square test was used to determine the significance of risk factors (gender, age, and maintenance methods) with a significance value $(\alpha)$ of 0.05 .

\section{Results}

\section{Respondents}

There were 38 animal owner respondents, most of whom $(86.84 \%)$ were male. Nearly three-quarters of respondents were $\geq 40$ years old. Only seven respondents were educated to at least high school or college level. Most respondents (89.47\%) were farmers, and others were civil servants or traders.

\section{Prevalence of schistosomiasis in animals}

The main species assessed were buffaloes (maintained formeat, working animals, and traditional events), cattle (meat and traditional events), pigs (meat and traditional events), and horses (working animals). The total number of animals consisted of cattle, buffaloes, horses, pigs, and dogs living in the Lindu Subdistrict. There were 134 animal fecal samples, including 59 pigs, 28 horses, 26 buffaloes, 13 cattle, and 8 dogs from five villages (Anca, Tomado, Puroo, Langko, and Olu villages). S. japonicum infection rate in cattle, buffalo, horses, dogs, and pigs is shown in Table-1. Overall, the schistosomiasis prevalence was $32.9 \%$ (95\% CI 25.5 41.2\%). S. japonicum prevalence was highest in cattle (61.5\%; 95\% CI 54.2-68.8\%), while the lowest infection rate of S. japonicum was observed in dogs $(12.5 \%$; 95\% CI 4.5-20.5\%) (Table-1).

\section{Risk factors for schistosomiasis in animals}

In pigs, the only significant risk factor of $S$. japonicum infection was animal husbandry management $(p<0.000)$. The odds ratio of penned pigs versus free-roaming pigs was 8.667 (95\% CI 2.51029.929), which means that free-range pigs will probably be infected by S. japonicum 8.667 times more than pigs kept in cages (Table-2). Age and sex were not deemed as risk factors for schistosomiasis in pigs (both $\mathrm{p}>0.05$ ). All of the cattle sampled were adults and were kept in cages at night. However, from morning until the evening, they were allowed to graze in the grazing area. The prevalence of male cattle was slightly higher $(66.67 \%)$ than female $(60.00 \%)$, but sex was not determined as a risk factor of schistosomiasis in cattle as this difference was not statistically significant $(p>0.05)$. Similar to cattle, all buffaloes sampled were kept in cages at night and released to the grazing area during the day. Buffalo calves had a higher prevalence $(35.71 \%)$ than adult buffalo $(25.00 \%)$, but this difference was not statistically significant $(\mathrm{p}>0.05)$. The prevalence of schistosomiasis in male buffalo (41.67\%) was higher than the prevalence in female buffalo $(22.73 \%)$, but this was also not significantly different $(p>0.05)$. All of the horses sampled in the study were adults. The horses were free-range. No male horse was identified as infected by S. japonicum, while $28.00 \%$ of female horses were positive. However, statistically, sex was not a significant risk factor for schistosomiasis in horses $(p>0.05)$. No risk factors were identified as

\begin{tabular}{|c|c|c|c|c|c|c|c|}
\hline \multirow[t]{3}{*}{ Animal species } & \multicolumn{6}{|c|}{ Number of positive animals/sampled animals } & \multirow[t]{3}{*}{ Prevalence in \% $(95 \% \mathrm{CI})$} \\
\hline & \multicolumn{5}{|c|}{ Village } & \multirow[t]{2}{*}{ Total } & \\
\hline & Anca & Tomado & Langko & Puroo & Olu & & \\
\hline Cattle & $7 / 11$ & - & - & - & $1 / 2$ & $8 / 13$ & $61.5(54.2-68.8)$ \\
\hline Buffalo & $0 / 2$ & $0 / 4$ & $11 / 20$ & - & - & $11 / 26$ & $43.3(39.6-47.0)$ \\
\hline Horse & - & - & $7 / 28$ & - & - & $7 / 28$ & $25.0(22.0-28.0)$ \\
\hline Pig & $0 / 18$ & $0 / 1$ & $10 / 15$ & $4 / 16$ & $7 / 9$ & $21 / 59$ & $35.6(34.0-37.2)$ \\
\hline Dog & - & $1 / 5$ & $0 / 3$ & - & - & $1 / 8$ & $12.5(4.5-20.5)$ \\
\hline Total & $7 / 31$ & $1 / 10$ & $28 / 66$ & $4 / 16$ & $8 / 11$ & $47 / 134$ & $32.9(25.5-41.2)$ \\
\hline
\end{tabular}
significant in $\operatorname{dogs}(\mathrm{p}>0.05)$.

As shown in Table-2, the infection intensity was highest in horses (the arithmetic and the geometric mean

Table-1: Prevalence of S. japonicum infection in each species and village in the Lindu Subdistrict based on the Danish Bilharziasis Laboratory method.

$\mathrm{CI}=$ Confidence interval, $S$. japonicum=Schistosoma japonicum 
of eggs per gram feces were 25.2 and 7.0 , respectively). Dogs had the lowest arithmetic and geometric mean values for eggs per gram of feces of 2.0 and 2.0, respectively. The results of the mapping regarding the distribution of animals infected with $S$. japonicum in the Lindu Subdistrict are shown in Figure-1. Figure-1 shows the distribution of animals suffering from $S$. japonicum infection and their overlapping host range with the $O$. hupensis lindoensis snail foci.

\section{Contamination index for host species}

The mean daily mass of excreted feces per host each species has been published previously [17]. The ACI (the total number of daily eggs discharged) was, $1,720,000$, $1,980,000,1,764,000,172,200$, and 300 , for cattle, buffaloes, horses, pigs, and dogs, respectively (Table-2).

The population of cattle, buffalo, horses, dogs, and pigs was obtained from the Sigi district Animal Husbandry and Animal Health Service (2017) [19]. In this study, the survey coverage (i.e. the number of animals sampled divided by the total population) of cattle, buffalo, horses, dogs, and pigs were $7.6 \%$, $4.5 \%, 16.7 \%, 4.3 \%$, and $7.0 \%$, respectively. There were $94,640,883$ eggs released by all infected animals each day. Table-3 shows the RTI, which indicates each species role in the transmission of $S$. japonicum infection. The data on eggs per gram of feces shown in Table- 3 are based on the DBL technique. The relative contribution of buffaloes in schistosomiasis transmission in the Lindu Subdistrict was the greatest $(62.3 \%)$ followed by cattle $(24.03 \%)$ and horses $(11.18 \%)$. The contributions of pigs and dogs in S. japonicum transmission were not significant, with an RTI of only $2.39 \%$ and $0.05 \%$, respectively (Table- 3 ). The calculations indicated that 94,640,883 S. japonicum eggs were released every day by all of the animals in the Subdistrict of Lindu (Table-3).

\section{Discussion}

Since 1937, the Lindu Subdistrict has been known as an endemic area for schistosomiasis japonica. Brug and Tesch were the first to report the presence of $S$. japonicum eggs in autopsied human bodies in Palu Hospital [4]. There is still disease transmission in this area. In Indonesia, the surveillance of

Table-2: The prevalence, intensity of infection (arithmetic and the geometric mean of eggs per gram of feces), and animal contamination index of S. japonicum in animals in the Lindu Subdistrict.

\begin{tabular}{lccccc}
\hline Species & $\begin{array}{c}\text { Number of } \\
\text { samples }\end{array}$ & $\begin{array}{c}\text { Number of } \\
\text { positive } \\
\text { samples }\end{array}$ & $\begin{array}{c}\text { Prevalence in } \\
\text { percentage } \\
\text { (95\% CI) }\end{array}$ & $\begin{array}{c}\text { The arithmetic } \\
\text { mean of egg per } \\
\text { gram of feces }\end{array}$ & $\begin{array}{c}\text { The geometric } \\
\text { mean of egg per } \\
\text { gram of feces }\end{array}$ \\
\hline Cattle & 13 & 8 & $61.5(54.2-68.8)$ & 8.6 & 5.7 \\
contamination \\
index
\end{tabular}

$\mathrm{CI}=$ Confidence interval, $\mathrm{S}$. japonicum=Schistosoma japonicum

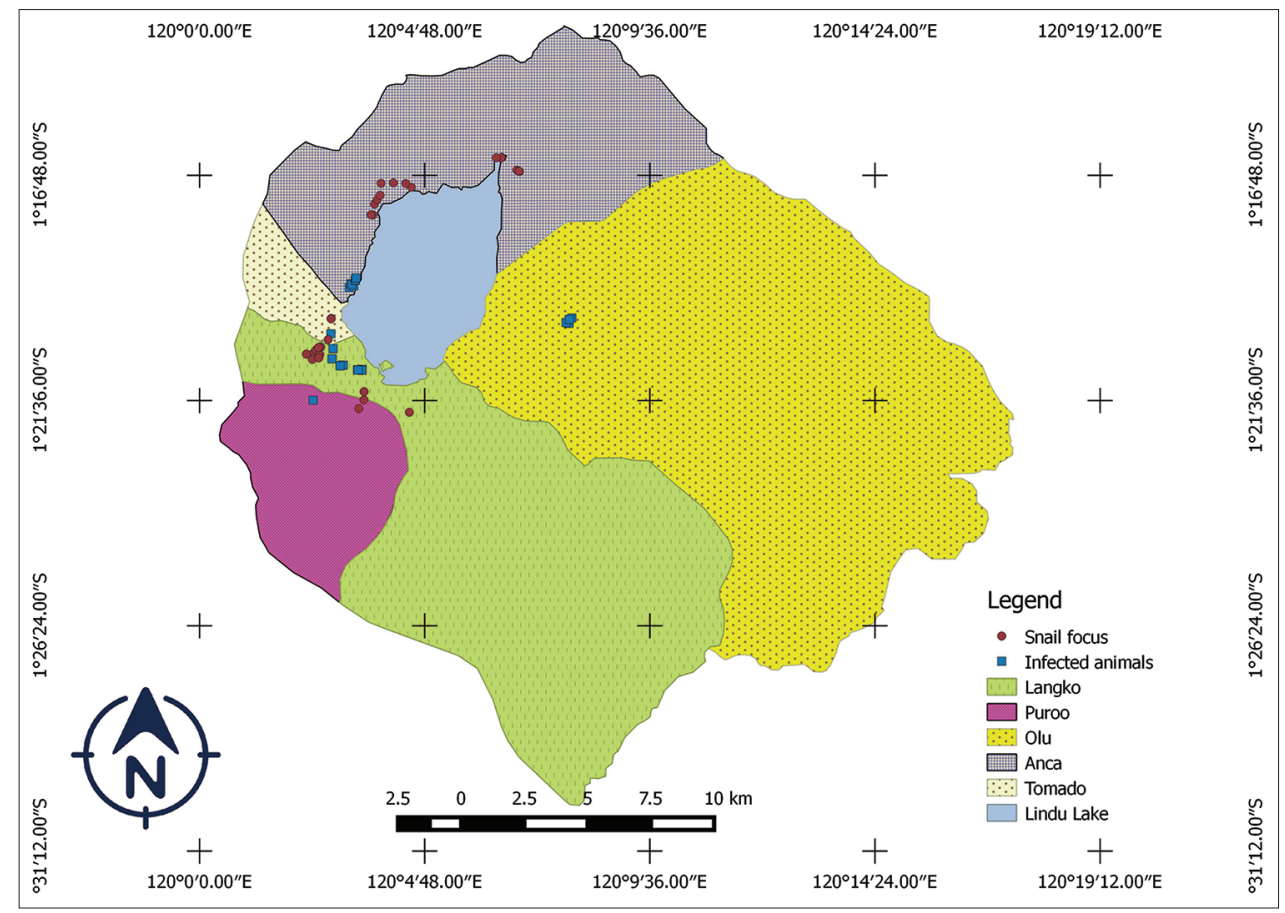

Figure-1: Map of schistosomiasis japonica spread among animals in the Lindu Subdistrict. [Source: Map was illustrated by Novericko Ginger Budiono] 
Table-3: Total daily egg excretion and relative transmission index of S. japonicum in the Subdistrict of Lindu.

\begin{tabular}{lcccccccc}
\hline $\begin{array}{l}\text { Animal } \\
\text { species }\end{array}$ & $\begin{array}{c}\text { Number } \\
\text { of animal } \\
\text { population }\end{array}$ & $\begin{array}{c}\text { Number } \\
\text { of animals } \\
\text { examined }\end{array}$ & $\begin{array}{c}\text { Number } \\
\text { of positive } \\
\text { animals }\end{array}$ & $\begin{array}{c}\text { Prevalence } \\
(\%)\end{array}$ & $\begin{array}{c}\text { The arithmetic } \\
\text { mean of egg per } \\
\text { gram of feces }\end{array}$ & $\begin{array}{c}\text { Weight of } \\
\text { feces (g) }\end{array}$ & $\begin{array}{c}\text { Total } \\
\text { daily egg } \\
\text { excretion }\end{array}$ & $\begin{array}{c}\text { Relative } \\
\text { transmission } \\
\text { index } \%)\end{array}$ \\
\hline Cattle & 172 & 13 & 8 & 61.5 & 8.6 & 25,000 & $22,742,700$ & 24.03 \\
Buffalo & 757 & 26 & 11 & 43.3 & 7.2 & 25,000 & $59,000,580$ & 62.34 \\
Horse & 168 & 28 & 7 & 25 & 25.2 & 10,000 & $10,584,000$ & 11.18 \\
Pig & 842 & 59 & 21 & 35.6 & 16.4 & 500 & $2,263,128$ & 2.39 \\
Dog & 1346 & 8 & 1 & 12.5 & 2 & 150 & 50,475 & 0.05 \\
Total & 3285 & 134 & 47 & 32.9 & & $94,640,883$ & \\
\hline
\end{tabular}

S. japonicum=Schistosoma japonicum

schistosomiasis in endemic areas, including the Lindu Subdistrict, is performed twice a year to measure the prevalence of schistosomiasis in humans, snails $(O$. hupensis lindoensis), and rodents (as reservoir hosts). Unfortunately, schistosomiasis surveillance in mammals (other than humans and rodents) is not continuous. There is particular concern regarding schistosomiasis because it is zoonotic, meaning that non-mammalian hosts can also act as reservoir hosts when they are infected with $S$. japonicum. For instance, reports of infections in mammals other than rodents in the Lindu Subdistrict were recently reported by Gunawan et al. [20]. Budiono et al. [21] also indicated the presence of trematode infections, including $S$. japonicum, in cattle and buffaloes in Lindu and other endemic locations. According to the author's knowledge, no one has reported the RTI of each mammalian species (humans and other mammals) in the Lindu Subdistrict.

The primary animal commodities in the Lindu Subdistrict are buffaloes, pigs, and beef cattle. Although there are few reports of schistosomiasis infection in animals, there have been no specific interventions to provide treatment (in the form of praziquantel) for infected animals. Therefore, there is still a knowledge gap that needs to be filled with research aimed at investigating the prevalence of schistosomiasis in animals and their relative contribution to transmitting the disease to humans. This is a pilot study that seeks to answer the hypothesis that domestic animals help spread schistosomiasis in humans in the Lindu Subdistrict. The DBL technique was used to detect the presence of $S$. japonicum eggs in domestic animal feces.

This study reported that the overall $S$. japonicum infection in five domestic animal species in the Lindu Subdistrict was 32.9\% (95\% CI 25.5-41.2\%). The prevalence of schistosomiasis in this study is slightly higher than a previous report by Gunawan et al. [20], amounting to $24.66 \%$ from a total of 219 animal samples infected by $S$. japonicum. This difference in prevalence may be due to differences in the examination methods used. Gunawan et al. [20] conducted the S. japonicum infection survey in 2013 with a formalin-ether sedimentation testing technique, a different sample size, and a different survey time. This result was also in contrast with a previous study by Izhar et al. [22], which reported that there was no $S$. japonicum infection among 202 animals (water buffaloes, horses, dogs, pigs, and cows) examined in the Lindu Subdistrict.

There has been a fluctuation in the prevalence of schistosomiasis in humans in the Lindu Highlands in recent years (between 2012 and 2017), fluctuating from $1.22 \%, 0.72 \%, 0.90 \%, 1.24 \%, 0.92 \%$, to $0.85 \%$, from year to year, respectively [23]. Repeated infections can contribute to this fluctuation. In each village, the prevalence of human schistosomiasis in 2017 was $0.69 \%$ in Anca, $0.37 \%$ in Tomado, $2.14 \%$ in Puroo, $0.73 \%$ in Langko, and $0.36 \%$ in Olu [23].

In 2016, S. japonicum infection in the O. hupensis lindoensis snail, sampled from the Lindu Subdistrict, varied from 1.2 to $14.5 \%$ [23]. In recent studies $[24,25]$, it was reported that in the Anca Village of the Subdistrict of Lindu, a total of 12 O. hupensis lindoensis snail foci were present with a total area of 19,784 $\mathrm{km}^{2}$. In the Langko village, there was one focus of $O$. hupensis lindoensis snail that was found with a cumulative area of $6886 \mathrm{~km}^{2}$. In the village of Puroo, there were three $O$. hupensis lindoensis snail foci with a total area of $487,546 \mathrm{~km}^{2}$, while in the Olu village, no $O$. hupensis lindoensis snail focus found. Based on schistosomiasis distribution maps reported by Sudomo and Carney [8], the area which is now known as Olu is an endemic area for schistosomiasis. This is shown in Figure-1, where the locations that animals are likely to be infected by $S$. japonicum are around the focus of the O. hupensis lindoensis snail. Further study is needed to identify the presence of current snail foci in the Olu village.

This study uses the assumptions of daily body weight released by each animal species at the study site based on the previous research [16,17] regarding the total stool weight released per day by each species. It would be better if measurements were taken directly from each animal species at the study site. Researchers may find it difficult to measure some free-range animals.

The DBL technique was used to determine $S$. japonicum infection in a wide range of animals, namely, cattle, horses, buffaloes, dogs, cats, and rats, with high specificity ( $>92 \%)$ and high sensitivity $(80-96 \%)[15,26]$. The advantages of the DBL technique are that it is (1) easy to apply; (2) a quantitative diagnostic test; and (3) non-toxic; it (4) can distinguish living and dead eggs; (5) can be reread for 
quality control; and (6) can be used to diagnose infections by other trematodes such as Fasciola gigantica, Paramphistome, Dicrocoelium dendriticum, and Plagiorchis javensis [21,26-28].

In the present study, the DBL technique was used as described by Carabin et al. [26] for detecting $S$. japonicum infection in a range of animal species. Further research is necessary to identify each animal species' actual contribution to schistosomiasis transmission, such as miracidia hatchability and the actual defecation of animals in snail foci. A previous study has also reported that each different animal species tended to excrete a different hatching rate of $S$. japonicum. It would be better if the amount of S. japonicum miracidia hatched per gram of stool could be determined rather than the number of $S$. japonicum eggs per gram of stool [17]. The infection rate of $S$. japonicum in all domestic mammal species in the Subdistrict of Lindu is still relatively high $(>5 \%)$.

Infected animals are a vital source of infection and play a role in spreading the disease. In each particular endemic area, each mammal species is considered to play a respective role in $S$. japonicum transmission. Domestic animals residing in endemic areas are susceptible to $S$. japonicum infection, but their relative contribution to the spread of $S$. japonicum eggs may be different. The leading causes of the spread of eggs are environmental factors and management practice. Studies in China revealed that, in the highlands, nocturnal rodents are the predominant hosts. The intermediate hosts shed the cercariae in the evening, while in the lowlands, bovines are the main shedders of $S$. japonicum eggs in the early morning when they come into contact with water [29]. In general, water buffaloes expelled more feces compared with cattle and other species. Therefore, water buffaloes are considered the most significant contributors to disease transmission [17]. The high prevalence of schistosomiasis in large livestock is affected by the animals' continuous exposure to $S$. japonicum cercariae infections in the snail foci locations as a result of free-grazing patterns and the lack of praziquantel treatment.

This study succeeded in showing that large ruminants, namely, buffaloes and cattle, also played an essential role in disseminating $S$. japonicum eggs to the environment. This was evidenced by the deposition of $62.3 \%$ and $24.3 \%$ S. japonicum eggs by buffaloes and cows, respectively, in the Lindu Highland. Cattle and buffaloes are bred as animal protein sources and as working animals for agricultural purposes. The animal owners let the livestock, especially ruminants, to graze in disease transmission areas. This study's results support the results of the previous research in China that cattle, buffaloes, and goats are the animals most involved in schistosomiasis japonica transmission [17,30-36]. Bovines have been considered one of the main contributors of $S$. japonicum transmission in China because they live in large populations, have long life spans, are free-roaming, and can excrete a high number of eggs into the environment [9]. This study also noted the importance of horses as potential $S$. japonicum reservoir hosts as schistosomiasis prevalence in the horse was found to be relatively high $(25.0 \%)$ (95\% CI 22.0-28.0\%). The results show that these animals have an important role in the spread of $S$. japonicum infection to humans in Indonesia. Infection of bovines and horses by $S$. japonicum can occur while they graze or drink around ditches or water bodies contaminated by $S$. japonicum cercariae. The use of untreated animal excrement as agricultural fertilizer can also be an indirect source of contamination of S. japonicum eggs in the field. Biogas treatment, which creates an anaerobic atmosphere, of animal stool samples can prevent $S$. japonicum egg contamination due to a lack of oxygen.

Another potential host of $S$. japonicum is the pig. Our results show that 21 of 59 pigs $(35.6 \%)$ were infected with $S$. japonicum. Pigs in the Lindu Subdistrict are mostly retained in pens, which reduces the risk of S. japonicum infection. This was identified in this study where pigs that were reared in a freerange environment were 8.667 times more susceptible to $S$. japonicum compared with pigs kept in cages. This, therefore, suggests that the rearing of pigs in a free-range environment is a significant risk factor in $S$. japonicum infection. This is in agreement with another study that concluded that penned animals could reduce transmission potential [17].

Our study reported that one of eight dogs tested were infected with S. japonicum. Infection of dogs with $S$. japonicum has rarely been studied as it is difficult to sample the stools from this species. The present study reported that dogs are not essential contributors to schistosomiasis transmission, justified by low rates of $S$. japonicum infection compared to other species, but there was still $>5 \%$ transmission rate in dogs, which is still significant. The low rates of infection in dogs may be caused by limited contact with contaminated water. Another study by Wang et al. [17] also reported a low prevalence of schistosomiasis in dogs. As dogs in the Lindu Subdistrict are free-range, they can probably be infected by S. japonicum while drinking from or defecating in, small water bodies or ditches.

In the Philippines, there is a paradigm shift that buffaloes were thought to previously be considered insignificant in the spread of schistosomiasis japonica, but based on recent findings, it has now been agreed that they play an essential role in transmission [18]. In the Western Samar Province, dogs and rats were known to have a role in the transmission of $S$. japonicum into humans. Rats were also used as sentinel animals to determine the spread of schistosomiasis japonica in an endemic area [15].

The high prevalence of schistosomiasis japonica in animals in Lindu in this study shows the need for an integrated intervention program in animals. Control measures in China proved that the mass administration of praziquantel to animals could reduce $S$. japonicum 
infection in both humans and animals [9], but it cannot inhibit recurring infection. Developing a schistosomiasis control program requires a database, wherein relevant information regarding disease transmission dynamics is contained. Therefore, an approach is needed to be able to determine the level of infection between the intermediate host and the definitive host [37]. This study is the first step in understanding the level of schistosomiasis japonica in domestic animals as a definitive host separate from humans. This study can complement a database, considering that, schistosomiasis surveillance in domestic animals is still limited and not continuous. Besides, we need to integrate intervention in the form of praziquantel chemotherapy in animals, combined with other schistosomiasis control programs, and to reduce infection rates and control schistosomiasis in Lindu. To date, in Indonesia, there has never been an intervention trial with the administration of praziquantel drugs to provide treatment to animals. This research will be beneficial as a basis for developing schistosomiasis control programs in the future.

\section{Conclusion}

The prevalence of schistosomiasis japonica in animals in the Lindu Subdistrict is high. In pigs, freerange rearing is a significant risk factor for infection with S. japonicum. This study concluded that cattle, buffalo, and horses were the primary source of $S$. japonicum infection in the Subdistrict of Lindu. In addition to other control measures, in endemic areas, the treatment of animals, which act as $S$. japonicum reservoir hosts, with praziquantel, is needed, especially in the Subdistrict of Lindu, to achieve the goal of schistosomiasis eradication by 2025 . Further study is also needed to understand the number of hatched $S$. japonicum eggs per gram of feces.

\section{Authors' Contributions}

FS designed the study. NGB conducted the experiment, analyzed the data, and wrote the first draft of the manuscript. FS, YR, EH, and SM contributed to the drafting and revision of the manuscript. All authors read and approved the final manuscript.

\section{Acknowledgments}

This study was supported by a grant (PMDSU scheme) from the Ministry of Research, Technology, and Higher Education, the Republic of Indonesia (Grant number: 136/SP2H/LT/DPRM/IV/2017). The study is part of Ph.D. research of Novericko Ginger Budiono under the Master Program of Education Leading to Doctoral Degree for Outstanding Graduate (PMDSU) scholarship.

\section{Competing Interests}

The authors declared that they have no competing interests.

\section{Publisher's Note}

Veterinary World remains neutral with regard to jurisdictional claims in the published map and institutional affiliation.

\section{References}

1. Colley, D.G., Bustinduy, A.L., Secor, W.E., and King, C.H. (2014) Human schistosomiasis. The Lancet, 383(9936): 2253-2264.

2. Wang, X.Y., Xu, J., Zhao, S., Li, W., Zhang, J.F., He, J., Swing, A.M., and Yang, K. (2018) Estimating the prevalence of schistosomiasis japonica in China: A serological approach. Infect. Dis. Poverty, 7(1): 62.

3. Tchuenté, L.A.T., Rollinson, D., Stothard, J.R. and Molyneux, D. (2017) Moving from control to elimination of schistosomiasis in sub-Saharan Africa: Time to change and adapt strategies. Infect. Dis. Poverty, 6(1): 42.

4. Satrija, F., Ridwan, Y., Jastal, J., Samarang, S. and Rauf, A. (2015) Current status of schistosomiasis in Indonesia. Acta Trop. 141(Pt B): 349-353.

5. Magalhaes, R.J.S., Salamat, M.S., Leonardo, L., Gray, D.J., Carabin, H., Halton, K., McManus, D.P., Williams, G.M., Rivera, P., Saniel, O., Hernandez, L., Yakob, L., McGarvey, S. and Clements, A. (2014) Geographical distribution of human Schistosoma japonicum infection in the Philippines: Tools to support disease control and further elimination. Int. J. Parasitol., 44(13): 977-984.

6. Zou, L. and Ruan, S. (2015) Schistosomiasis transmission and control in China. Acta Trop., 143(2015): 51-57.

7. Gordon, C., Kurscheid, J., Williams, G., Clements, A., Li, Y., Zhou, X.N., Utzinger, J., McManus, D. and Gray, D. (2019) Asian schistosomiasis: Current status and prospects for control leading to elimination. Trop. Med. Infect. Dis., 4(1): 40.

8. Sudomo, M. and Carney, W.P. (1974) Pre control investigation of schistosomiasis in Central Sulawesi. Indones. Bul. Health Res., 2(2): 51-60.

9. Williams, G.M., Li, Y.S., Gray, D.J., Zhao, Z.Y., Harn, D.A., Shollenberger, L.M., Li, S.M., Yu, X., Feng, Z., Guo, J.G., Zhou, J., Dong, Y.L., Li, Y., Guo, B., Driguez, P., Harvie, M., You, H., Ross, A.G. and McManus, D.P. (2019) Field testing integrated interventions for schistosomiasis elimination in the people's republic of China: Outcomes of a multifactorial cluster-randomized controlled trial. Front. Immunol., 10(645): 1-14.

10. Yu, J.M., de Vlas, S.J., Jiang, Q.W. and Gryseels, B. (2007) Comparison of the Kato-Katz technique, hatching test and indirect hemagglutination assay (IHA) for the diagnosis of Schistosoma japonicum infection in China. Parasitol. Int., 56(1): 45-49.

11. Fernandez, T. Jr., Tarafder, M., Balolong, E. Jr., Joseph, L., Willingham, A. $3^{\text {rd }}$, Belisle, P., Webster, J., Olveda, R., McGarvey, S. and Carabin, H. (2007) Prevalence of Schistosoma japonicum infection among animals in fifty villages of Samar Province, the Philippines. Vector Borne Zoonotic Dis., 7(2): 147-155.

12. Vale, N., Gouveia, M.J., Rinaldi, G., Brindley, P.J., Gärtner, F. and Da Costa, J.M.C. (2017) Praziquantel for schistosomiasis: Single-drug metabolism revisited, mode of action, and resistance. Antimicrob. Agents Chemother., 61(5): 1-16.

13. Statistics Indonesia. (2018) Lindu Sub-district in Number 2018. Statistics Indonesia, Indonesia.

14. Thrusfield, M., Christley, R., Brown, H., Diggle, P.J., French, N., Howe, K., Kelly, L., O’Connor, A., Sargeant, J. and Wood, H. (2018) Veterinary Epidemiology. $4^{\text {th }}$ ed. Wiley Blackwell, Oxford, the United Kingdom.

15. Carabin, H., McGarvey, S.T., Sahlu, I., Tarafder, M.R., Joseph, L., De Andrade, B.B., Balolong, E. and Olveda, R. (2015) Schistosoma japonicum in Samar, the Philippines: Infection in dogs and rats as a possible risk factor for human infection. Epidemiol. Infect., 143(8): 1767-1776. 
16. Suryanto, S. (2010) Theoretical Foundation and Equestrian Sports Center Program in Surakarta is a Complex Scope of Buildings Emphasizing Post Modern Architectural Design, Thesis. Universitas Katolik Sugijapranata, Yogyakarta.

17. Wang, T.P., Maria, V.J., Zhang, S.Q., Wang, F.F., Wu, W.D., Zhang, G.H., Pan, X.P., Ju, Y. and Niels, Ø. (2005) Transmission of Schistosoma japonicum by humans and domestic animals in the Yangtze River valley, Anhui province, China. Acta Trop., 96(2-3): 198-204.

18. Gordon, C.A., Acosta, L.P., Gobert, G.N., Jiz, M., Olveda, R.M., Ross, A.G., Gray, D.J., Williams, G.M., Harn, D., Li, Y. and McManus, D.P. (2015) High prevalence of Schistosoma japonicum and Fasciola gigantica in bovines from Northern Samar, the Philippines. PLoS Negl. Trop. Dis., 9(2): e0003108.

19. Department of Animal Health and Husbandry. (2017) Animal Data in Sigi District 2017. Department of Animal Health and Husbandry, Sigi District.

20. Gunawan, G., Anastasia, H., Pamela, F.S.P. and Risti, R. (2014) Contribution animal mammal cattle, buffalo, horse, pig and dog in infection schistosomiasis in Subdistrict Lindu, district Sigi, Central of Sulawesi Province 2013. Media Health Res. Dev., 24(4): 209-214.

21. Budiono, N.G., Satrija, F., Ridwan, Y., Nur, D. and Hasmawati, H. (2018) Trematodoses in cattle and buffalo around schistosomiasis endemic areas in Central Sulawesi Province of Indonesia. Indones. J. Agric. Sci., 23(2): 112-126.

22. Izhar, A., Sinaga, R., Sudomo, M., and Wardiyo, N. (2002) Recent situation of schistosomiasis in Indonesia. Acta Trop., 82(2): 283-288.

23. Ministry of National Development Planning and Ministry of Health, Republic of Indonesia. (2018) Schistosomiasis Eradication Road Map 2018-2025. Ministry of National Development Planning and Ministry of Health, Republic of Indonesia, Indonesia.

24. Widjaja, J., Anastasis, H., Nurwidayati, A., Nurjana, M.A., Mujiyanto, M. and Maksud, M. (2017) Current situation of intermediate snail focus in schistosomiasis endemic area of Central Sulawesi. Indones. Bull. Health Res., 45(4): 215-222.

25. http://www.schisto.sulteng.gov.id. Positive snail foci. Retrieved on 20-10-2019.

26. Carabin, H., Balolong, E., Joseph, L., McGarvey, S., Johansen, M., Fernandez, T., Willingham, A. and Olveda, R. (2005) Estimating sensitivity and specificity of a faecal examination method for infection in cats, dogs, water buffaloes, pigs, and rats in Western Samar and Sorsogon Provinces, the Philippines. Int. J. Parasitol., 35(14): 1517-1524.

27. Anh, N.T.L., Phuong, N.T., Ha, G.H., Thu, L.T., Johansen, M.V., Murrell, D.K. and Thamsborg, S.M. (2008) Evaluation of techniques for detection of small trematode eggs in feces of domestic animals. Vet. Parasitol., 156(3-4): 346-349.
28. Lumain, J.P.L. and Balala, L. (2018) Suitability of Danish Bilharziasis laboratory technique (dbl) as a detection test for trematode infection in buffaloes. CLSU Int. J. Sci. Technol., 3(2): $1-8$

29. Webster, J.P., Borlase, A. and Rudge, J.W. (2017) Who acquires infection from whom and how? Disentangling multi-host and multi-mode transmission dynamics in the elimination era. Philos. Trans. R. Soc. B Bio. Sci., 372(1719): 20160091

30. Gray, D.J., Chen, H., Li, Y., Williams, G.M., Feng, Z., Forsyth, S.J., Guo, J., Li, R.S., Barnett, A.G. and McManus, D.P. (2007) A cluster-randomized bovine intervention trial against Schistosoma japonicum in the people's republic of China: Design and baseline results. Am. J. Trop. Med. Hyg., 77(5): 866-874.

31. Gray, D.J., Williams, G.M., Li, Y., Chen, H., Forsyth, S.J., Li, R.S., Barnett, A.G., Guo, J., Ross, A.G., Feng, Z. and McManus, D.P. (2009) A cluster-randomised intervention trial against Schistosoma japonicum in the peoples' republic of China: Bovine and human transmission. PLoS One, 4(6): e5900.

32. Guo, J., Li, Y., Hu, G., McManus, D.P., Sleigh, A.C., Chen, H., Williams, G.M., Feng, Z., Gray, D., Ning, A. and Davis, G.M. (2006) A drug-based intervention study on the importance of buffaloes for human Schistosoma japonicum infection around Poyang Lake, people's republic of China. Am. J. Trop. Med. Hyg., 74(2): 335-341.

33. Guo, J.G., Ross, A.G., Lin, D.D., Williams, G.M., McManus, D.P., Chen, H.G., Li, Y., Davis, G.M., Feng, Z. and Sleigh, A.C. (2001) A baseline study on the importance of bovines for human Schistosoma japonicum infection around Poyang Lake, China. Am. J. Trop. Med. Hyg., 65(4): 272-278.

34. Li, H., Liu, J., Song, J., Ma, S., Wang, Q., Heng, L., Yu, Z., Liu, Y., Yang, A. and Dong, G. (2014) Domestic animal schistosomiasis in 2012 in China. Chin. J. Anim. Infect. Dis., 22(5): 68-71.

35. Liu, J., Zhu, C., Shi, Y., Li, H., Wang, L., Qin, S., Kang, S., Huang, Y., Jin, Y. and Lin, J. (2012) Surveillance of Schistosoma japonicum infection in domestic ruminants in the Dongting Lake region, Hunan Province, China. PLoS One, 7(2): e31876.

36. Wu, H.W., Acosta, L., Meng, R., Ji, M.J., Liu, Y., McGarvey, S.T., Olveda, R., Qin, Y.F., Friedman, J.F., Chu, K. and Kurtiz, J.D. (2010) High prevalence of Schistosoma japonicum infection in water buffaloes in the Philippines assessed by real-time polymerase chain reaction. Am. J. Trop. Med. Hyg., 82(4): 646-652.

37. Cao, Z., Huang, Y. and Wang, T. (2017) Schistosomiasis japonica control in domestic animals: Progress and experiences in China. Front. Microbiol., 8(2464): 1-5. 